\title{
Latitudinal trends of species diversity in rocky intertidal herbivore assemblages: spatial scale and the relationship between local and regional species richness
}

\author{
Marcelo M. Rivadeneira, Miriam Fernández*, Sergio A. Navarrete \\ Estación Costera de Investigaciones Marinas and Center for Advanced Studies in Ecology and Biodiversity, \\ Departamento de Ecología, Facultad de Ciencias Biológicas, Pontificia Universidad Católica de Chile, \\ Casilla 114-D, Santiago, CP 6513667, Chile
}

\begin{abstract}
In this study we assessed the impact of the spatial scale of analysis on patterns of latitudinal diversity of rocky intertidal invertebrates and on the relationship between local and regional species richness. Fifty-three wave-exposed sites were sampled along the coast of Chile between $18^{\circ} 40^{\prime} \mathrm{S}$ and $42^{\circ} 35^{\prime} \mathrm{S}$, covering a range of over $2600 \mathrm{~km}$ and $25^{\circ}$ of latitude. Three spatial scales were defined to analyze latitudinal trends of diversity: (1) regional, based on species range limits across the entire region (100s of km), (2) site, corresponding to hundreds of square meters sampled at each location, (3) sampling unit scale, corresponding roughly with a square meter of rocky shore. The analysis showed that spatial patterns of species richness and species turnover varied according to the scale used. At a regional scale, species richness showed a mid-latitudinal peak (i.e. around 30 to $32^{\circ} \mathrm{S}$ ), decreasing toward northern and southern latitudes. No clear latitudinal trends in diversity were detected at site and especially at sampling unit scales. Despite the fact that at regional scale species turnover was low and geographically uniform, at the site scale beta diversity showed the existence of 2 zones of higher species turnover ( 19 to $20^{\circ} \mathrm{S}$ and 30 to $32^{\circ} \mathrm{S}$ ), which may be attributed to changes in ecological and oceanographical regimes. The relationship between regional and local species richness changed depending on the 'local' scale used; unsaturated patterns (linear positive relationship between local and regional diversity) were evident at site scale, whereas saturated patterns (quadratic trend between local and regional diversity) were observed when the local scale was defined in terms of the sampling unit. We suggest that different regulating processes, operating at different spatial scales, may explain the latitudinal trends in diversity at site and sampling unit scales. While regional processes may set an upper limit in species richness at site scale, species interactions (e.g. competition) may control species richness at sampling unit scales. These findings question the current idea of the disproportionate prevalence of regional factors over local ones in determining diversity of local assemblages. They also suggest that regulation of local diversity results from the interplay of regional and local processes.
\end{abstract}

KEY WORDS: Species diversity $\cdot$ Species saturation - Scale-dependence $\cdot$ Latitudinal gradient Rocky intertidal

\section{INTRODUCTION}

Among the spatial patterns of species diversity, the latitudinal gradient of species richness, in which the number of species peaks in the tropics and decreases

*Corresponding author. Email: mfernand@genes.bio.puc.cl toward higher latitudes, is one of the most consistent yet intriguing patterns in ecology (Rosenzweig 1995). Independent studies have shown that disparate taxa of terrestrial and marine organisms exhibit similar latitudinal trends in diversity. However, important exceptions do occur. For instance, in the marine realm, the latitudinal diversity gradient appears to be less consis- 
tent across taxa (Clarke \& Crame 1997); whereas some taxa exhibit a clear tropical increase in diversity (Rex et al. 1993, Roy et al. 1994, 1998, 2000, Clarke \& Crame 1997, Crame \& Clarke 1997, Clarke \& Lidgard 2000), others show no trend or even the inverse pattern (macroalgae: Santelices \& Marquet 1998, mollusks: Valdovinos et al. in press). Comparative studies analyzing differences across taxa, ecosystems and hemispheres can greatly advance our understanding of species diversity and may have consequences for the conservation of the world's biota. However, whether such differences in latitudinal trends reflect real differences in the response of plant and animal assemblages to large-scale environmental gradients, or whether they are simply the consequence of differences in the spatial scale of analysis of the different studies, has not yet been fully evaluated. It has long been shown that similar patterns of diversity at regional or global scales can be achieved by differences in gamma (regional), beta (between habitat), or alpha diversity, or through a combination of changes in diversity at all spatial scales (Whittaker 1975). Conversely, different trends in diversity can be obtained depending on the resolution or spatial scale at which species richness is measured (Clarke \& Crame 1997, Clarke \& Lidgard 2000).

The manner in which diversity changes across spatial scales influences the emergent pattern of latitudinal trends and reflects the interplay of regional and local processes (Ricklefs 1987, Cornell \& Lawton 1992, Cornell \& Karlson 1997). It has been proposed that the relationship between regional and local diversity can be used to test for community saturation and hence evaluate the importance of local factors in setting an upper bound to local richness (Terborgh \& Faaborg 1980, Cornell 1985a,b, Cornell \& Lawton 1992). Several studies have demonstrated the prevalence of unsaturated communities in different ecosystems and taxa (e.g. terrestrial vertebrates, invertebrates and plants: Caley \& Schluter 1997; tropical corals: Cornell \& Karlson 1997; insects: Cornell 1985a,b, and see Srivastava 1999 for review), supporting the idea that regional processes control local diversity. In the few marine studies in which the relationship has been tested, unsaturated patterns of diversity have been reported (Karlson \& Cornell 1998 and see references in Srivastava 1999). For instance, Karlson \& Cornell (1998) concluded that, despite the documented existence of strong competitive interactions in tropical coral communities, local assemblages are unsaturated and controlled by regional processes. In unsaturated assemblages, a linear positive relationship is observed between regional and local diversity, suggesting that local assemblages are subject to successful invasion by species from the regional pool, and that local processes, such as competition, do not set a ceiling on the maximum number of species. Lack of evidence showing saturated communities, even when intense competition has been experimentally demonstrated, could be explained by the methodological problems or artifacts introduced when compiling the information (Huston 1999, Loreau 2000). According to Huston (1999), strong species interaction and therefore saturated patterns would be found if the spatial scale at which local diversity is measured were small enough to reflect species interactions. Thus, the regional-local relationship is expected to be strongly dependent on the scale at which 'local community' is defined (Loreau 2000), and in most published studies the local scale to evaluate species interactions has simply been too large $\left(2500 \mathrm{~km}^{2}\right)$ to detect the effect of species interactions (Huston 1999).

Large-scale patterns (100s to $1000 \mathrm{~s}$ of $\mathrm{km}$ ) of diversity based on estimates of alpha diversity at local scales (100s of $\mathrm{m}$ ) are not readily available, although some notable exceptions exist (e.g. Rex et al. 1993, Clarke \& Lidgard 2000). In most cases, large-scale patterns of diversity are based on regional estimates of diversity resulting from the compilation of previously published information about geographical ranges of species. Thus, despite the important advances in the description of diversity patterns and underlying processes, widely dissimilar scales of analysis have jeopardized the identification of regional or local processes in determining diversity of local assemblages. In this study, we describe the latitudinal pattern of diversity of a rocky intertidal herbivore assemblage along the Pacific coast of South America based on both direct field surveys and literature compilations. By examining patterns of diversity at 3 different spatial scales, regional $(100 \mathrm{~s}$ of $\mathrm{km})$, site $(100 \mathrm{~s}$ of $\mathrm{m})$ and sampling unit $(\mathrm{m})$, we characterized the relationship between regional and local diversity and assessed the effect of spatial scales in the emergent patterns.

\section{MATERIALS AND METHODS}

Study sites and field surveys. Rocky shore surveys were carried out between September 1998 and February 2000 in 53 sites along ca. $3500 \mathrm{~km}$ of the Chilean coast, from $18^{\circ} 20^{\prime} \mathrm{S}$ to $42^{\circ} 35^{\prime} \mathrm{S}$ (Fig. 1). At least 1 site per degree of latitude was sampled along the $25^{\circ}$ latitude encompassed by the study. All surveys were conducted by the same research team, which minimized biases related to differences in sampling protocols. All sites were fully exposed to wave action. A description of the ecology of rocky shores along the Chilean coast can be found in Santelices (1990), Fernández et al. (2000) and Broitman et al. (2001). Human exploitation of marine invertebrates, algae and fish is an important feature of rocky intertidal communities along the 


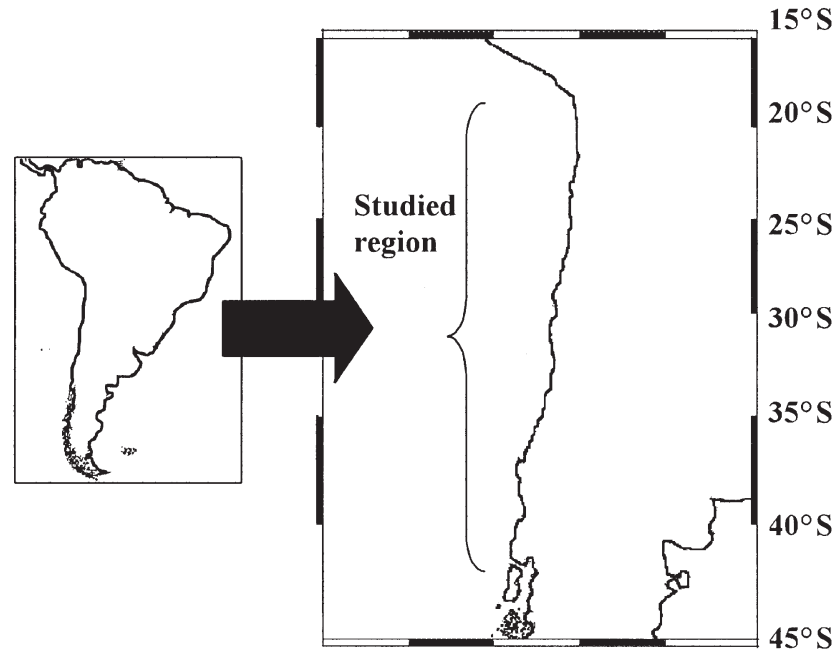

Fig. 1. Map of South American Pacific coast, showing the study region between $18^{\circ} 20^{\prime} \mathrm{S}$ and $42^{\circ} 35^{\prime} \mathrm{S}$, along the coast of Chile

entire coast of Chile (Castilla 1993, 1999). The potential effects of harvesting by humans on diversity patterns are discussed below.

Sampling was centered on herbivore grazers, the most diverse invertebrate assemblage of temperate rocky intertidal communities along the SE Pacific (Camus 1998, Broitman et al. 2001). Our analyses encompassed species from several taxa, including chitons, gastropods and sea urchins, but since in the area only 2 sea urchins inhabit the intertidal zone, species richness was mainly determined by mollusks. Several of these herbivores are key species in structuring intertidal communities (Santelices et al. 1981, Moreno \& Jaramillo 1983, Jara \& Moreno 1984, Santelices 1990). Other herbivore species, such as amphipods and fish, may also be important in regulating algal abundance in specific intertidal microhabitats (Buschmann \& Santelices 1987, Ojeda \& Muñoz 1999), but they were not sampled because of logistic difficulties (small size, high mobility) and limited sampling time. Micromollusk species smaller than ca. $1 \mathrm{~mm}$ of adult body size were not included in this study. To provide a good representation of the rocky intertidal zone, we sampled across different tidal levels and microhabitats, which included: low, mid and high zones of intertidal platforms (between 0 and $45^{\circ}$ of inclination), mid and high zones of vertical walls ( $\geq 75^{\circ}$ of inclination), boulders (between 20 and $50 \mathrm{~cm}$ diameter), and tidal pools (between 50 and $300 \mathrm{~cm}$ maximum diameter). Not all microhabitat and tidal height combinations were found at all sites. The low zone of vertical walls was not sampled because hazardous conditions prevented effective sampling at most sites. Low, mid and high intertidal levels were classified in the field according to well-known zonation patterns (Castilla 1981, Santelices
1990, Broitman et al. 2001). At each microhabitat, we looked for and removed all organisms encountered in a 5 min intensive search of the rocks, resulting in sampling areas between 0.25 and $1 \mathrm{~m}^{2}$. At least 5 separate searches per microhabitat and 25 per site were made.

Since all sites were visited only once, temporal changes in diversity correlated with latitude could modify the reported patterns. To shed light on the magnitude of temporal fluctuations in diversity, we evaluated inter-annual variation in total species richness per site in a subset of 9 sites located in central Chile, which were re-sampled in summer 2001. For this subset of sites at least, there was a positive and significant correlation in total species richness between years ( $\mathrm{r}=0.66, \mathrm{p}=0.05, \mathrm{n}=9$ ) and there were no significant changes in mean species richness per site (Student $t$-test for paired samples, $t=1.10$, df $=8, \mathrm{p}=$ $0.30)$. These results suggest that latitudinal trends of species diversity may well be characterized by a snapshot sampling.

Estimates of regional and local species diversity. We considered the regional pool of species as being the set of species sampled at least once in this study, assuming that species were continuously distributed between their reported northern and southern geographic limits. In addition, for those species reported as having either northern or southern ranges of distribution within the study region, our database improved the precision of their limits of distribution. Since this definition of regional richness is restricted to species found in field surveys, we could have underestimated the true regional species pool, especially with respect to rare or cryptic species. To minimize this bias, we searched the literature for all herbivore species (belonging to the groups considered in this study) reported in rocky intertidal habitats (Marincovic 1973, Zamorano \& Moreno 1975, Romo \& Alveal 1977, Santelices et al. 1977, 1980, Castilla 1981, Brattström \& Johanssen 1983, Cancino \& Santelices 1984, Vásquez \& Santelices 1984, Otaíza \& Santelices 1985, Camus 1998). Based on this search, we found 3 grazer species that were never encountered in field surveys, and they were incorporated into the analyses. Variation in regional species richness along the coast was then estimated by adding all species whose geographic ranges overlapped 1-degree latitudinal bands along the 25 bands considered in the study. A species rarefaction curve (sensu Gotelli \& Colwell 2001) was constructed to determine whether the regional pool of species was being underestimated. The rarefaction curve was based on 100 randomizations of the 53 sites sampled (EstimateS $5^{1}$ ) and 48 species. A total of 51 herbivore grazer species was identified as belonging to the study region, including the 3 species not encountered in field surveys but reported for this region in the literature. 
Our sampling effort along the coast seemed sufficient to characterize patterns of regional diversity (see 'Results').

Two spatial scales of local species richness were considered: (1) site species richness, defined as the total number of species found at each site during the surveys, and (2) sampling unit species richness, defined as the mean number of species per plot found at each site. To evaluate whether the sampling effort devoted to each site could adequately estimate site species richness, randomized species rarefaction curves using EstimateS 5 software ${ }^{1}$ were plotted for the 3 richest and the 3 poorest sites. Our sampling effort per site seemed adequate to characterize site diversity (see 'Results'), as defined by the extension of the coast covered by all sampling units in a given location.

To evaluate changes in species composition along the latitudinal gradient, we calculated beta diversity at (1) regional, and (2) site scales. Beta diversity was calculated as $\beta \mathrm{j}=1$ - Jaccard's index of similarity (Magurran 1988). At the regional scale, beta diversity was estimated between adjacent $1^{\circ}$ latitudinal bands using data of species latitudinal distribution obtained from the literature (see above). At site scale, beta diversity was estimated between adjacent sites based on field survey data. Since previous studies have shown strong discrepancies in species turnover trends depending on the beta diversity index used (Clarke \& Lidgard 2000), Whittaker's index was also estimated and its correlation with Jaccard's index calculated. Latitudinal trends in beta diversity (1 Jaccard) were evaluated using a 5 -site running average smoothing.

The relationship between regional and local species richness was assessed separately using the site and sampling unit scales. Since the maximum resolution of data compiled from the literature (regional scale) was $1^{\circ}$ latitude, we averaged all sites sampled within a latitudinal band. This procedure prevented lack of independence when statistically comparing local and regional trends (see Srivastava 1999). The shape of the relationship was tested by fitting polynomial (secondorder) regressions, forcing the intercept to zero, and testing for significance of the quadratic term, which illustrates the existence of unsaturated or saturated diversity patterns (Cornell \& Karlson 1997, Srivastava 1999).

Because apparent saturation can arise as an artifact produced by the underlying species-area relationship (i.e. pseudosaturation; Srivastava 1999, Shurin et al.

${ }^{1}$ Colwell RK (1997) EstimateS: Statistical estimation of species richness and shared species from samples. Version 5. User's guide and application available at: http://viceroy.eeb.uconn. edu/estimates
2000), we performed an analysis to take into account the possible effect of changes in the intertidal area across the region. A rough estimate of the total area available to intertidal organisms was provided by the average vertical extent or range of spring tides for each latitudinal band (Armada de Chile 2001). Since we found no correlation between regional diversity and tidal range $(\mathrm{r}=-0.05, \mathrm{p}=0.79, \mathrm{n}=25)$, pseudosaturation effects produced by varying constraints in available area across the region were expected to be small or absent.

\section{RESULTS}

\section{Rarefaction curves}

Based only on those species found in field surveys (48 species), regional richness reached the asymptotic maximum after about 35 sites had been sampled (Fig. 2a) while species richness at site scale reached the asymptotic number of replicates after 25 sampling units had been searched (Fig. 2b).

\section{Latitudinal gradients of species diversity}

Species richness varied with latitude in a slightly different fashion for the different spatial scales analyzed (Fig. 3). Latitudinally, regional species richness reached a maximum of 50 species around 30 to $32^{\circ} \mathrm{S}$, decreasing toward higher and lower latitudes to a minimum of 37 to 39 species per latitudinal band toward the extremes of the study region. The hump-back trend of regional richness was evident from the significance of the second-order term of polynomial quadratic regression (Table 1). At either site or sampling unit scales, no latitudinal trend was evident (Fig. 3) and both linear and quadratic terms of polynomial regressions were non-significant (Table 1). In spite of this lack of significant regional trend, some spatial patterns can be observed. At site scale, species richness was most variable around 32 to $36^{\circ} \mathrm{S}$, where maximum (27 species) and minimum (12) values were reached. This variation occurred over sites less than $20 \mathrm{~km}$ apart, which could show up to 2-fold variation in species richness (Fig. 3). Nevertheless, when site species richness was pooled between adjacent sites (i.e. the total number of species at both sites) a clearer latitudinal trend was evident, which tended to follow the regional pattern of diversity (Fig. 3). At sampling unit scale, the strongest species richness occurred between 29 and $32^{\circ} \mathrm{S}$, with a 4 -fold variation in species richness in $180 \mathrm{~km}$ (between 1.2 and 4.5 species per sampling unit; Fig. 3). 

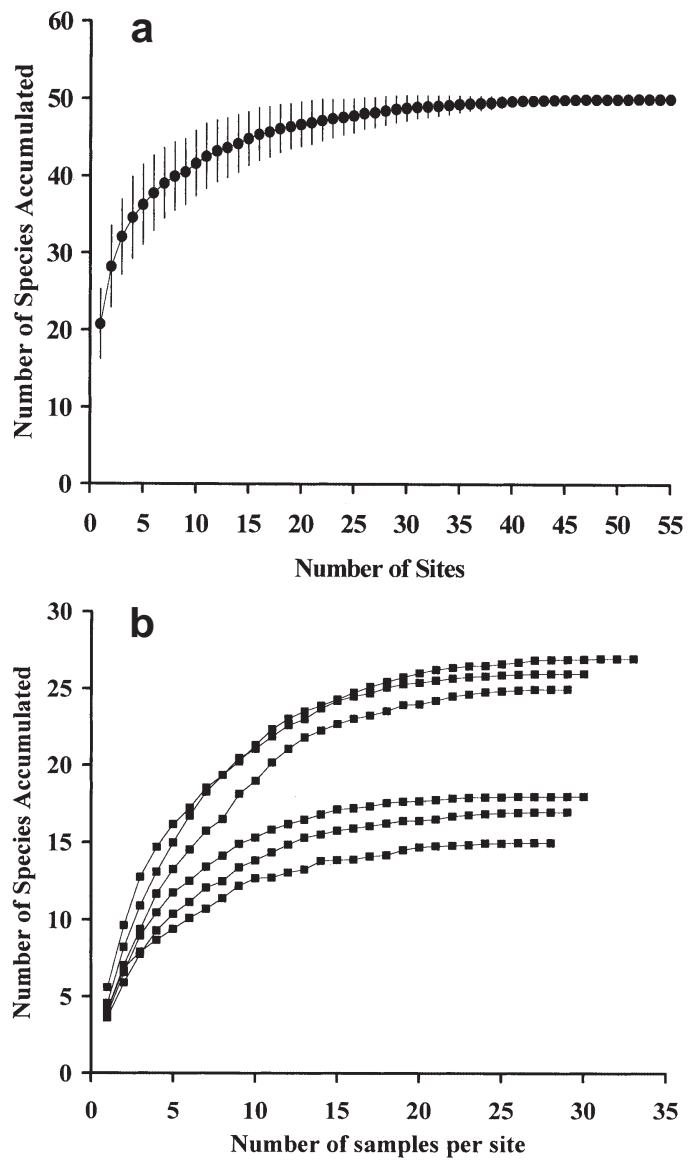

Fig. 2. (a) Rarefaction curve for the regional pool of species (mean and standard deviations) based on the number of sites sampled. The asymptotic curve indicates that total species richness in the region was reached after sampling ca. 35 sites. (b) Rarefaction curve for the species richness for the 3 richest (top 3 curves) and the 3 poorest sites (lower 3 curves) based on the number of replicates per site. In all cases, rarefaction curves reached asymptotic values after ca. 25 samples. All calculations were performed using the EstimateS 5 program $^{1}$

Beta diversity along the study region showed different patterns between the regional and site spatial scales (Fig. 4). At the regional scale species turnover between adjacent latitudinal bands was low (overall mean dissimilarity, $\beta \mathrm{j}=0.02, \mathrm{SD}=0.03, \mathrm{n}=$ 24), never exceeding $10 \%$ dissimilarity. At the site scale, species turnover was high (overall mean dissimilarity, $\beta \mathrm{j}=0.38, \mathrm{SD}=0.09, \mathrm{n}=52$ ) and highly variable among sites (range of $\beta \mathrm{j}=$ 0.23 to 0.57 ). Between sites a few kilometers apart, species turnover could be as high as $47 \%$ (e.g. around 32 to $\left.33^{\circ} \mathrm{S}\right)$. The running average smoothing showed a latitudinal peak in spe-

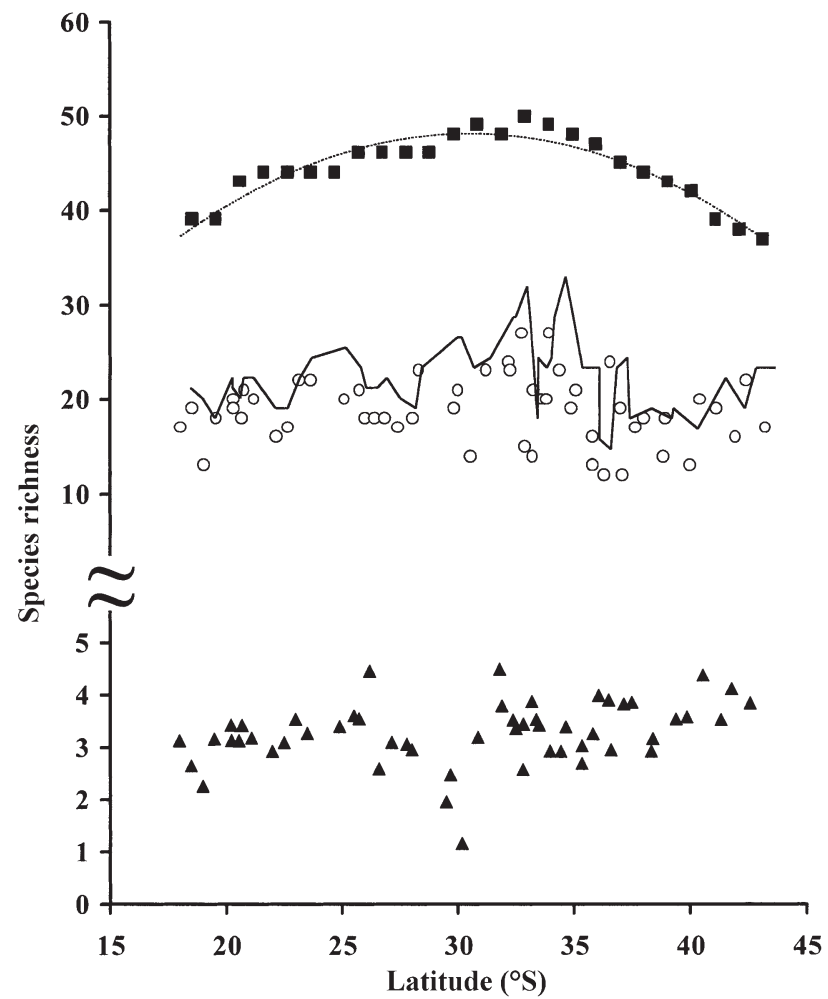

Fig. 3. Latitudinal trends of species richness for the herbivore grazer assemblage along the study region. Regional richness $(\boldsymbol{\square})$; site richness $(\mathrm{O})$; sampling unit richness $(\mathbf{\Lambda})$. Continuous line shows the total number of species accumulated between 2 adjacent sites. Dotted line shows a second-order polynomial fit

cies turnover in central Chile around 30 to $32^{\circ} \mathrm{S}$, where a 55 to $56 \%$ dissimilarity was estimated, with decreasing trends to the north and south (Fig. 4). At about 19 to $20^{\circ} \mathrm{S}$, species turnover increased again, reaching a dissimilarity of $50 \%$. The Whittaker's and 1 - Jaccard indexes showed similar trends, as evidenced by high correlations between the indexes at the regional $(\mathrm{r}=$ $0.99, \mathrm{p}<0.0001, \mathrm{n}=24)$ and site scales $(\mathrm{r}=0.98, \mathrm{p}<$ $0.0001, \mathrm{n}=52)$.

Table 1. Latitudinal trends of variation in species richness at 3 spatial scales Summary of second-order polynomial regressions between species richness at each spatial scale and latitude. Significant $p$-values at alpha $=0.05$ are in bold

\begin{tabular}{|c|c|c|c|c|c|c|}
\hline Spatial scale & $\mathrm{n}$ & $\mathrm{R}^{2}$ & Term & Slope & $\mathrm{SE}$ & $\mathrm{p}$-value \\
\hline Regional & 25 & 0.90 & $\begin{array}{l}\text { Latitude } \\
\text { (Latitude) }\end{array}$ & $\begin{array}{r}4.417 \\
-0.073\end{array}$ & $\begin{array}{l}0.317 \\
0.005\end{array}$ & $\begin{array}{l}<0.001 \\
<0.001\end{array}$ \\
\hline Site & 53 & 0.07 & $\begin{array}{l}\text { Latitude } \\
\text { (Latitude) })^{2}\end{array}$ & $\begin{array}{r}1.127 \\
-0.020\end{array}$ & $\begin{array}{l}0.624 \\
0.010\end{array}$ & $\begin{array}{l}0.077 \\
0.067\end{array}$ \\
\hline Sampling unit & 53 & 0.13 & $\begin{array}{l}\text { Latitude } \\
\text { (Latitude) })^{2}\end{array}$ & $\begin{array}{r}-0.106 \\
0.002\end{array}$ & $\begin{array}{l}0.102 \\
0.002\end{array}$ & $\begin{array}{l}0.305 \\
0.198\end{array}$ \\
\hline
\end{tabular}




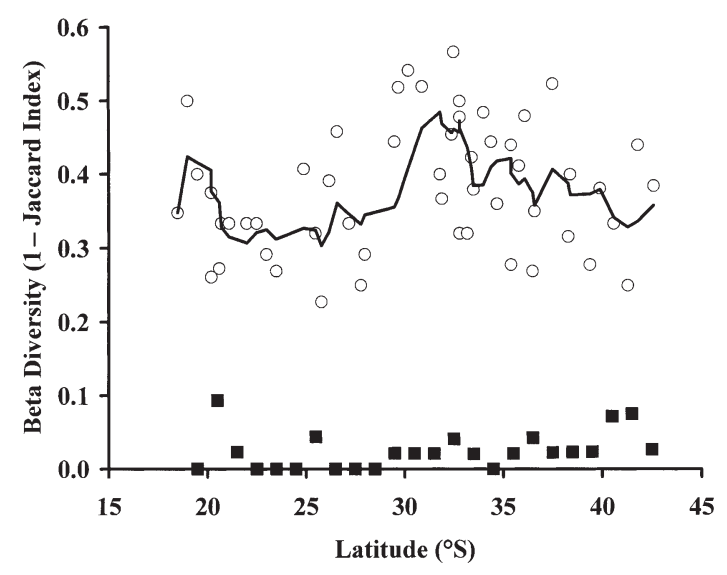

Fig. 4. Latitudinal variation in species turnover between adjacent sites $(0)$ and between adjacent latitudinal bands ( $\square$ ). Beta diversity (1 - Jaccard's index of similarity) was calculated between adjacent sites or latitudinal bands across the latitudinal gradient. Line represents a 5-sites running average smoothing

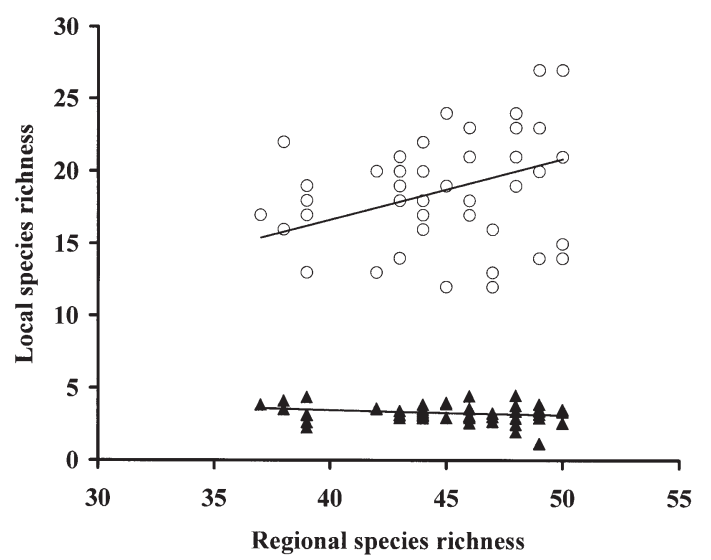

Fig. 5. Relationship between regional and local species richness at $(0)$ site scale and $(\boldsymbol{\Delta})$ sampling unit scale. Each point represents a site $(n=53)$. Line shows the fitted model in each case, based on mean values of all the sites within each $1^{\circ}$ latitudinal band ( 25 bands)

\section{Relationship between regional and local species richness}

The relationship between regional and local richness varied depending on the spatial scale used for the analysis (Fig. 5, Table 2). On the one hand, site species richness showed a significant linear relationship with regional species richness (Table 2), with no evident ceiling or curvilinear trend, suggesting an unsaturated pattern (Table 2, Fig. 5). The trend was evident in spite of large dispersion in the data. On the other hand, both linear (but negative) and quadratic terms of the poly-
Table 2. Relationship between regional and local richness Summary of polynomial regressions performed at both site and sampling unit scales. In all cases the intercepts were forced to zero. Significant $p$-values at alpha $=0.05$ are in bold

\begin{tabular}{|lcrrr|}
\hline Local scale & Term & Slope & SE & p-value \\
\hline Site & Regional & 0.550 & 0.131 & $\mathbf{< 0 . 0 0 1}$ \\
& (Regional) $^{2}$ & -0.003 & 0.003 & 0.319 \\
Sampling & Regional & 0.190 & 0.029 & $\mathbf{< 0 . 0 0 1}$ \\
unit & (Regional) $^{2}$ & -0.003 & 0.001 & $<\mathbf{0 . 0 0 1}$ \\
\hline
\end{tabular}

nomial regression model were significant when the sampling unit was used to define the local scale, suggesting that a plateau of sampling unit richness had been reached (Table 2, Fig. 5). In fact, sampling unit richness tended to decrease at high levels of regional species richness.

\section{DISCUSSION}

Our results provide empirical evidence for a scaledependence in the relationship between local versus regional diversity. Depending on the spatial scale of analysis, one can conclude that local rocky intertidal assemblages are either saturated (sampling unit scale) or unsaturated of species (site scale), judging by the existence of significant quadratic or linear relationship between 'local' and regional diversity (e.g. Cornell \& Lawton 1992). Although such scale dependency had been hypothesized (Cornell \& Karlson 1997), previous attempts have failed to demonstrate it using field data (e.g. Caley \& Schluter 1997), apparently because the local scale of analysis used in those studies (i.e. $2500 \mathrm{~km}^{2}$ ) was too large to observe the outcome of species interactions leading to species exclusion (Houston 1999). Therefore, positive significant relationships between local and regional diversity were bound to be observed in those studies, and so far unsaturated assemblages appear as the prevailing pattern (Cornell \& Karlson 1997). The smallest local scale of our study (i.e. sampling unit) was about $1 \mathrm{~m}^{2}$, and although it was large enough to fit several hundreds of individuals of most species, it seems to have been small enough to capture the consequences of species interactions (e.g. some form of competition), when and if they occurred.

The observed pattern of scale dependence of the relationship between local and regional diversity might reflect the existence of processes simultaneously operating on local assemblages but at different spatial scales. First, at the scale of site $\left(100 \mathrm{~s}\right.$ of $\left.\mathrm{m}^{2}\right)$, the total number of species correlates positively with regional diversity, suggesting that the regional pool primarily controls local species richness (Cornell 1985a,b, Rick- 
lefs 1987, Cornell \& Lawton 1992, Hawkins \& Compton 1992, Cornell \& Karlson 1997, Srivastava 1999, Shurin et al. 2000). However, regional diversity does not determine the actual number of species at any given site, but rather sets an upper limit to the total number of species. For instance, in central Chile, where maximum regional diversity was observed, we found the richest sites of the entire study region, but also some of the poorest (see Fig. 3). Rarefaction curves suggest that large among-site variability in species richness observed in central Chile is probably not the result of insufficient sampling, nor are there apparent differences in microhabitats among these sites. Variability in species richness could therefore be produced by unmeasured differences in microhabitat conditions or by among-site variability in the arrival or recruitment of species to different sites, which is probably related to variability in meso-scale nearshore oceanographic conditions along central Chile (Broitman et al. 2001, Poulin et al. 2002). As mentioned earlier, along the coast of Chile humans exploit many invertebrate and algal species, including many of those considered in this study, which can have a great impact on the structure of rocky intertidal communities (Castilla 1993, 1999, Fernández et al. 2000). However, to date no rigorous assessment has been made concerning the real impact of human harvesting on the species diversity of the whole intertidal community (see Durán \& Castilla [1989] for limited findings on primary space occupiers). Preliminary evidence from a comparison of sites with different degrees of access to humans (e.g. military bases, marine protected areas, open access zones) showed no differences in local diversity of grazers (M.M.R. unpubl. data), suggesting that human harvesting of grazers plays a minor role in determining the local diversity of this assemblage.

Second, the quadratic relationship between sampling unit and regional diversity suggests that the number of species is constrained by an upper limit, probably imposed by species interactions (e.g. Terborgh \& Faaborg 1980, Tonn et al. 1990). Thus, while at the scale of a site, species are seemingly able to invade the assemblage in proportion to richness of the regional pool, the successful colonization of a habitat patch of a few square meters appears to be restricted by the presence of other species. At sites occurring in areas of high regional diversity, local coexistence of species might be possible through an increase in patchiness within those sites, as hypothesized by Loreau (2000). Unfortunately, although competitive interactions among grazers seem to be important in other rocky intertidal shores (e.g. Fletcher \& Creese 1985, Ortega 1985, Branch \& Moreno 1994, Boaventura et al. 2002), there is little experimental information about the intensity of competition among the species that comprise the grazer assemblage that we studied. Studies by Godoy \& Moreno (1989) showed that competition between 2 grazer species could alter grazer growth rates and fecundity, which could affect population abundance. Field experiments in regions with contrasting herbivore diversity could reveal whether interspecific competition may limit sampling unit richness.

The above interpretation of unsaturated assemblages at the scale of site is based on the existence of a positive linear relationship between site and regional species richness when forcing the regression through the origin (e.g. Cornell \& Lawton 1992, Cornell \& Karlson 1997, Srivastava 1999). However, site species richness never exceeded $50 \%$ of total regional richness, which could be interpreted as processes restricting not the number of species but the proportion of the regional pool actually found within a site. It has been suggested that site richness can increase over time, from years to decades, approaching the regional pool of species (Kidwell \& Flessa 1996), and therefore our sampling would not capture the 'true' site species richness. This is unlikely, however, since limited evidence from central Chile suggests that year-to-year changes in species composition are rather minor (see 'Materials and methods'). Accumulation of species over decades does not explain why there is a reduced number of species that coexist at any given time. This problem has not been addressed in the literature, which opens new venues for field and theoretical research.

The lack of latitudinal trend in intertidal grazer diversity along the coast of Chile agrees well with the pattern reported by Valdovinos et al. (in press) using the entire mollusk biota and contrasts sharply with the pattern reported in the northern hemisphere (Roy 1998, 2000). Absence of strong latitudinal trends suggests that processes regulating or limiting diversity over regional scales are relatively homogeneous along this section of the coast. The possibility that processes that do vary latitudinally, e.g. sea surface temperature, could be direct determinants of latitudinal diversity patterns, is also ruled out.

Finally, since the number of species per sampling unit remains relatively unchanged across the entire region, despite changes in the regional pool of species, there could be important geographical differences in the probability that a particular species is excluded from a given patch (e.g. Tonn et al. 1990, Hawkins \& Compton 1992). On average, species would face a greater chance of patch extinction in central Chile (i.e. 30 to $32^{\circ} \mathrm{S}$ ), where regional diversity is higher, than toward higher and lower latitudes. Experimental studies are necessary to evaluate this proposition. Our results also highlight the potential danger of making decisions about conservation of diversity based only on 
compilation data, because estimates of regional diversity (usually the only information revealed by such a compilation approach) might not reflect actual diversity in the assemblages targeted for protective measures (i.e. high diversity regions can contain both richest and poorest sites). Moreover, our explicit scalebased approach provides the first empirical evidence supporting theoretical expectations that both regional and local processes can simultaneously shape local diversity, and that their relative importance changes with spatial scale of analysis.

Acknowledgements. The present contribution has been possible thanks to the collaboration of Sandra Cifuentes, Esteban Emparanza, Fernanda Oyarzún, Nathaly Ruiz-Tagle, Juan Luis Allendes, Athan Mandragouras, Erin Small, Bernardo Broitman and Fredy Véliz. Manuel Varas, Jorge Guerra, María Manosalva, Cantherine Rivadeneira, Joaquín PrietoRivadeneira and Loreto Bruna provided additional logistical support and encouragement during our field trips. Carmen Espoz, Jaime Ramírez, Rubén Soto, and Claudio Valdovinos provided assistance identifying species. Two anonymous referees and Juan Carlos Castilla provided valuable suggestions to improve this contribution. This work was funded by FONDAP (Oceanography and Marine Biology \#3). M.M.R. acknowledges financial support from CONICYT (doctoral fellowship) and support of the Lerner Gray Fund for Marine Research (American Museum of Natural History), as well as financial support from a grant of the Andrew Mellon Foundation to S.A.N. and J.C.C. The paper was completed during the tenure of FONDAP-Fondecyt grant 1501-0001 to the Center of Advanced Studies in Ecology and Biodiversity.

\section{LITERATURE CITED}

Armada de Chile (2001) Tablas de marea de la costa de Chile. Publicación No. 3009, Servicio Hidrográfico y Oceanográfico de la Armada de Chile, Valparaíso

Boaventura D, da Fonseca LC, Hawkins SJ (2002) Analysis of competitive interactions between the limpets Patella depressa Pennant and Patella vulgata L. on the northern coast of Portugal. J Exp Mar Biol Ecol 271:171-188

Branch GM, Moreno CA (1994) Intertidal and subtidal grazers. In: Sigfried WR (ed) Rocky shores: exploitation in Chile and South Africa. Springer-Verlag, Berlin, p 75-100

Brattström H, Johanssen A (1983) Ecological and regional zoogeography of the marine benthic fauna of Chile. Sarsia 68:289-339

Broitman B, Navarrete S, Smith F, Gaines S (2001) Geographic variation of southeastern Pacific intertidal communities. Mar Ecol Prog Ser 224:21-34

Buschmann A, Santelices B (1987) Micrograzers and spore release in Iridaea laminarioides Bory (Rhodophyta: Gigartinales). J Exp Mar Biol Ecol 108:171-179

Caley MJ, Schluter D (1997) The relationship between local and regional diversity. Ecology 78:70-80

Camus PA (1998) Estructura espacial de la diversidad en ensambles sésiles del intermareal rocoso de Chile centronorte: la diversidad local como resultado de determinantes de multiescala. PhD thesis, P. Universidad Católica de Chile

Cancino J, Santelices B (1984) Importancia ecológica de los discos adhesivos de Lessonia nigrescens Bory (Phaeophyta) en Chile central. Rev Chil Hist Nat 57:23-33
Castilla JC (1981) Perspectivas de investigación en estructura y dinámica de comunidades intermareales rocosas de Chile central. II. Depredadores de alto nivel trófico. Medio Ambiente 5:190-215

Castilla JC (1993) Humans: capstone strong actors in the past and present coastal ecological play. In: Mcdonnell MJ, Pickett STA (eds) Humans as components of ecological systems. Springer-Verlag, Berlin, p 158-162

Castilla JC (1999) Coastal marine communities: trends and perspectives from human-exclusion experiments. Trends Ecol Evol 14:280-283

Clarke A, Crame A (1997) Diversity, latitude and time: patterns in the shallow sea. In: Ormond RF, Gage JD, Angel MV (eds) Marine diversity: patterns and processes. Cambridge University Press, Cambridge, p 122-147

Clarke A, Lidgard S (2000) Spatial patterns of diversity in the sea: bryozoan species richness in the North Atlantic. J Anim Ecol 69:799-814

Cornell HV (1985a) Local and regional richness of cynipine gall wasps on California oaks. Ecology 66:1247-1260

Cornell HV (1985b) Species assemblages of cynipid gall wasps are not saturated. Am Nat 126:565-569

Cornell HV, Karlson RH (1997) Local and regional processes as controls of species richness. In: Tilman D, Kareiva P (eds) Spatial ecology: the role of space in population dynamics and interspecific interactions. Princeton University Press, Princeton, NJ, p 250-268

Cornell HV, Lawton JH (1992) Species interactions, local and regional processes, and limits to the richness of ecological communities: a theoretical perspective. J Anim Ecol 61: $1-12$

Crame JA, Clarke A (1997) The historical components of marine taxonomic diversity gradients. In: Ormond RF, Gage JD, Angel MV (eds) Marine diversity: patterns and processes. Cambridge University Press, Cambridge, p 258-273

Durán RL, Castilla JC (1989) Variation and persistence of middle rocky intertidal community of central Chile with and without human harvesting. Mar Biol 103:555-562

Fernández M, Jaramillo E, Marquet PA, Moreno CA, Navarrete SA, Ojeda FP, Valdovinos CR, Vásquez JA (2000) Diversity, dynamics and biogeography of Chilean benthic nearshore ecosystems: an overview and guidelines for conservation. Rev Chil Hist Nat 73:797-830

Fletcher WJ, Creese RG (1985) Competitive interactions between co-occurring herbivorous gastropods. Mar Biol 86: 183-191

Godoy C, Moreno CA (1989) Indirect effects of human exclusion from the rocky intertidal in southern Chile: a case of cross-linkage between herbivores. Oikos 54:101-106

Gotelli NJ, Colwell RK (2001) Quantifying biodiversity: procedures and pitfalls in the measurement and comparison of species richness. Ecol Lett 4:379-391

Hawkins BA, Compton SG (1992) African fig gasp communities: undersaturation and latitudinal gradients in species richness. J Anim Ecol 61:361-372

Huston MA (1999) Local processes and regional patterns: appropriate scales for understanding variation in the diversity of plants and animals. Oikos 86:393-401

Jara F, Moreno C (1984) Herbivory and structure in a midlittoral rocky community: a case in southern Chile. Ecology 65:28-38

Karlson RH, Cornell HV (1998) Scale-dependent variation in local vs. regional effects on coral species richness. Ecol Monogr 68:259-274

Kidwell SM, Flessa KW (1996) The quality of the fossil record: populations, species, and communities. Annu Rev Earth Planet Sci 24:433-464 
Loreau M (2000) Are communities saturated? On the relationship between $\alpha, \beta$ and $\gamma$ diversity. Ecol Lett 3:73-76

Magurran AE (1998) Ecological diversity and its measurement. Princeton University Press, Princeton, NJ

Marincovic L (1973) Intertidal molluscs of Iquique, Chile. Sci Bull Nat Hist Mus Los Angeles 16:1-49

Moreno CA, Jaramillo E (1983) The role of the grazers in the zonation of intertidal macroalgae of the Chilean coast near of Valdivia, Chile. Oikos 41:73-76

Ojeda FP, Muñoz AA (1999) Feeding selectivity of the herbivorous fish Scartichthys viridis: effects on macroalgal community structure in a temperate rocky intertidal coast. Mar Ecol Prog Ser 184:219-229

Ortega S (1985) Competitive interactions among tropical intertidal limpets. J Exp Mar Biol Ecol 90:21-25

Otaíza R, Santelices B (1985) Vertical distribution of chitons (Mollusca: Polyplacophora) in the rocky intertidal zone of central Chile. J Exp Mar Biol Ecol 86:229-240

Poulin E, Palma AT, Leiva G, Nárvaez D, Pacheco C, Navarrete SA, Castilla JC (2002) Avoiding offshore transport during upwelling events: the case of competent larvae of the gastropod Concholepas concholepas. Limnol Oceanogr 47: 1248-1255

Rex MA, Stuart CT, Hessler RR, Allen JA, Sanders HL, Wilson GD (1993) Global-scale latitudinal patterns of species diversity in the deep-sea benthos. Nature 365:636-639

Rhode K (1999) Latitudinal gradients in species diversity and Rapoport's rule revisited: a review of recent work and what can parasites teach us about causes of the gradients. Ecography 22:593-613

Ricklefs RE (1987) Community diversity: relative roles of local and regional processes. Science 235:167-171

Romo H, Alveal K (1977) Las comunidades del litoral rocoso de Punta Ventanilla Bahía de Quintero-Chile. Gayana Misc 6:1-41

Rosenzweig ML (1995) Species diversity in space and time. Cambridge University Press, Cambridge

Roy K, Jablonski D, Valentine JW (1994) Eastern Pacific molluscan provinces and latitudinal diversity gradient: no evidence for 'Rapoport's rule'. Proc Natl Acad Sci USA 91:8871-8874

Roy K, Jablonski D, Valentine JW, Rosenberg G (1998) Marine latitudinal diversity gradients: test of causal hypotheses. Proc Natl Acad Sci USA 95:3699-3702

Editorial responsibility: Otto Kinne (Editor),

Oldendorf/Luhe, Germany
Roy K, Jablonski D, Valentine JW (2000) Dissecting latitudinal diversity gradients: functional groups and clades of marine bivalves. Proc R Soc London B 267:293-299

Santelices B (1990) Patterns of organization of intertidal and shallow subtidal vegetation in wave exposed habitats of central Chile. Hydrobiologia 192:35-57

Santelices B, Marquet PA (1998) Seaweeds, latitudinal diversity patterns and Rapoport's Rule. Divers Distrib 4:71-75

Santelices B, Cancino J, Montalva S, Pinto R, González E (1977) Estudios ecológicos en la zona costera afectada por el contaminación del 'Northern Breeze'. Medio Ambiente 2:65-83

Santelices B, Castilla JC, Cancino J, Schmiede P (1980) Comparative ecology of Lessonia nigrescens and Durvillaea antarctica (Phaeophyta) in central Chile. Mar Biol 59: 119-132

Santelices B, Montalva S, Oliger P (1981) Competitive algal community organization in exposed intertidal habitats from central Chile. Mar Ecol Prog Ser 6:267-276

Shurin JB, Havel JE, Leibold MA, Pinel-Alloul B (2000) Local and regional zooplankton species richness: a scaleindependent test for saturation. Ecology 81:3062-6073

Srivastava DS (1999) Using local-regional richness plots to test for species saturation: pitfalls and potentials. J Anim Ecol 68:1-16

Terborgh JW, Faaborg J (1980) Saturation of birds communities in the West Indies. Am Nat 116:178-195

Tonn WM, Magnunson JJ, Martti R, Toivonen J (1990) Intercontinental comparison of small-lake fish assemblages: the balance between local and regional processes. Am Nat 136:345-375

Valdovinos C, Navarrete SA, Marquet PA (in press) Mollusk species diversity in the southern Pacific: why are there more species towards the pole? Ecography

Vásquez JA, Santelices B (1984) Comunidades de macroinvertebrados en discos adhesivos de Lessonia nigrescens Bory (Phaeophyta) en Chile central. Rev Chil Hist Nat 57: 131-154

Whittaker RH (1975) Communities and ecosystems. Macmillan, New York

Zamorano JH, Moreno CA (1975) Comunidades bentónicas del sublitoral rocoso de bahía corral. I. Area mínima de muestreo y descripción cuantitativa de la asociación de Pyura chilensis Molina. Medio Ambiente 1:58-66

Submitted: April 19, 2002; Accepted: August 28, 2002

Proofs received from author(s): November 18, 2002 